\section{Shingrix Vaccine and Guillain-Barre Syndrome: A Case Report}

Werdah Zafar, MBBS, Hunain Aslam, MBBS, Lakshmi P Digala, MBBS, and Raghav Govindarajan, MD Department of Neurology, University of Missouri Health Care, Columbia, MO. USA. 65201

Keywords: Shingrix vaccine, Guillain-Barre syndrome, Autoimmunity, Herpes Zoster.

\section{Introduction}

Herpes zoster (HZ), also known as Shingles, is caused by Varicella Zoster Virus (VZV), a member of the $\alpha$-herpes virus family. There are an estimated 1 million cases of $\mathrm{HZ}$ each year in the United States, and almost 1 out of every 3rd person will develop HZ in their lifetime. ${ }^{1} \mathrm{VZV}$ is usually acquired during childhood and remains latent in the dorsal root ganglion and becomes reactivated in advanced age or an immune-compromised state. If left untreated, HZ can cause complications such as post-herpetic neuralgia, meningoencephalitis, and permanent nerve damage.

To combat this increased incidence of the disease, primary prevention with the vaccination is the mainstay of treatment. Shingrix is a non-live recombinant vaccine that has recently been approved by CDC-Center for Disease Control and Prevention for HZ. It consists of glycoprotein $\mathrm{E}(\mathrm{gE})$ and an adjuvant component called ASO1B. ASOlB enhances the potency, quality, and longevity of the immune response. ${ }^{2} \mathrm{gE}$ is usually present on the surface of cells infected by the varicella-zoster virus. ${ }^{2} \mathrm{gE}$ is vital for viral replication and is also capable of inducing cellular and humoral immunity. Some components of the vaccine, such as $\mathrm{gE}$ or the ASOlB may be associated with the development of some autoimmune diseases through the process of molecular mimicry, epitope spreading, reactivation of memory $\mathrm{T}$ cells, or super antigenic $\mathrm{T}$ cell activation.

This report presents a case of Guillain- Barre syndrome that developed after the administration of the Shingrix Vaccine.

The Shingrix, a non-live recombinant vaccine, utilized to prevent herpes zoster infection. Some components of the vaccine may be associated with the development of some autoimmune diseases. We report a case of Guillain-Barre syndrome that developed after the administration of the Shingrix Vaccine.

\section{Case report}

A 79-year old male with a past medical history of clinically diagnosed neuropathy by his PCP, initially presented with symptoms of progressive tingling and numbness in his feet for over a week to the urgent care clinic. At the baseline, the patient was very active, and the history was negative for any other relevant symptoms. The neurological examination at the urgent care was reported unremarkable (no further details available). However, the patient reported receiving the Shingrix vaccine ten days before the onset of symptoms. Due to the patient's history of outdoor activities, he got empirically treated with doxycycline, and blood drawn for tick-borne serologies came back negative. He returned with worsening paresthesia and weakness in his legs, which culminated in a fall. A neurological examination done on this visit showed diminished pinprick and vibration bilaterally from the toes to the knees with areflexia at biceps, brachioradialis, patella, and Achilles despite Jendrassik maneuver. Romberg was positive, with no dysmetria on finger to nose test. His gait was broad-based. There was no loss of sensation in the upper limbs. Motor examination showed a weakness with foot dorsiflexion and medical research council- MRC grading of $4 / 5$ for bilateral hip flexion and knee extension.

Lumbar puncture showed elevated CSF Protein: 195 $\mathrm{mg} / \mathrm{dl}$, with a normal corrected WBC count. Electrodiagnostic study revealed demyelinating polyneuropathy (Table 1).

MRI of the lumbar spine with contrast showed enhancement of the ventral roots (Figure 1). The patient was

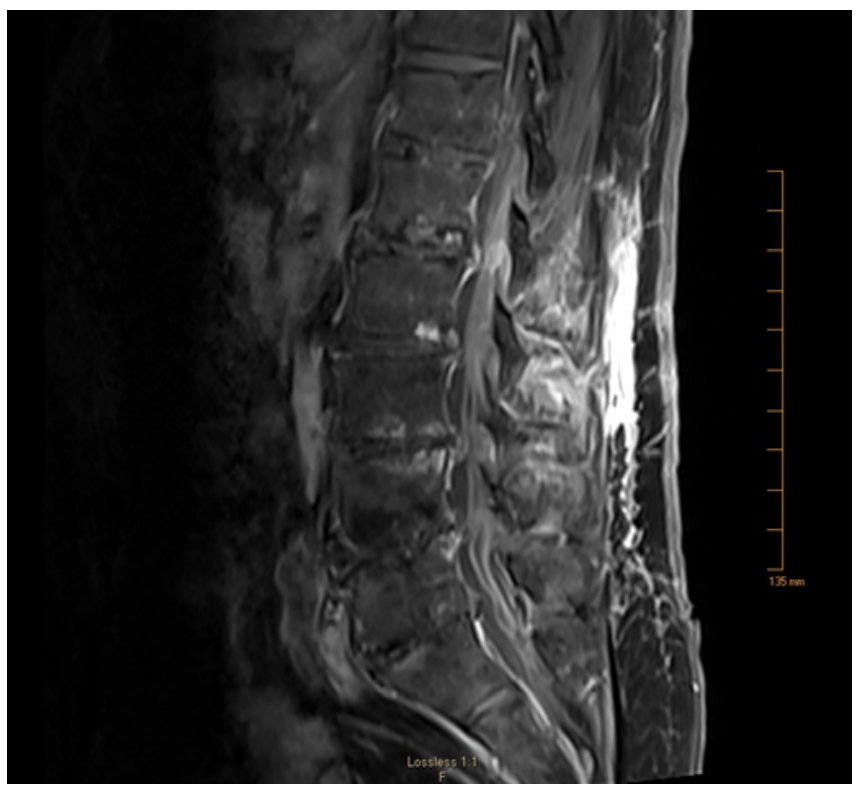

Figure 1 : MRI Lumbar Spine with and without contrast, T1 - Post contrast shows enlarged and enhancing nerve roots involving Ll through Sl. 
Table 1: Nerve Conduction Study (NCS) showing the evidence of a demyelinating polyneuropathy. The motor NCS shows prolonged latency and slowed conduction velocity in addition to reduced compound muscle action potential amplitudes in some nerves due to pre-existing neuropathy. $\mathrm{NR}=$ not recordable

\begin{tabular}{|c|c|c|c|}
\hline Nerve / Site & $\begin{array}{l}\text { Latency } \\
(\mathrm{m} / \mathrm{s})\end{array}$ & $\begin{array}{l}\text { CMAP } \\
\text { Amplitude } \\
(\mathrm{mV})\end{array}$ & $\begin{array}{c}\text { Conduction } \\
\text { Velocity }(\mathrm{m} / \mathrm{s})\end{array}$ \\
\hline Left Median & & & \\
\hline Wrist & 7.7 & 4.0 & \\
\hline Ref. & $<4.2$ & $>4.0$ & \\
\hline Elbow & 14.3 & 3.6 & 37.5 \\
\hline Ref. & & & 50 \\
\hline Right Ulnar & & & \\
\hline *Wrist & 4.2 & 7.2 & \\
\hline Ref. & $<3.6$ & $>5.0$ & \\
\hline Below Elbow & 10.3 & 6.0 & 41.3 \\
\hline Ref. & & & \\
\hline Above Elbow & 13.0 & 5.7 & 36.6 \\
\hline Ref. & & & 50 \\
\hline $\begin{array}{l}\text { Left } \\
\text { Peroneal }\end{array}$ & & & \\
\hline Ankle & NR & NR & NR \\
\hline Ref. & $<6.0$ & $>2.5$ & \\
\hline $\begin{array}{l}\text { Right } \\
\text { Peroneal }\end{array}$ & & & \\
\hline Ankle & NR & NR & NR \\
\hline Ref. & $<6.0$ & $>2.5$ & \\
\hline
\end{tabular}

\begin{tabular}{|c|c|c|c|}
\hline Left tibial & & & \\
\hline Ankle & 15.6 & 0.9 & \\
\hline Ref. & $<6.6$ & $>2.0$ & \\
\hline Knee & 32.2 & 0.3 & 27.1 \\
\hline Ref. & & & \\
\hline Right tibial & & & \\
\hline Ankle & 9.1 & 1.9 & \\
\hline Ref. & $<6.6$ & $>2.0$ & \\
\hline Knee & 27.1 & 1.1 & 25.2 \\
\hline Ref. & & & 40 \\
\hline $\begin{array}{l}\text { Left } \\
\text { Peroneal } \\
\text { Tibialis } \\
\text { Anterior }\end{array}$ & & & \\
\hline Fibular head & 4.0 & 4.0 & \\
\hline Ref. & $<4.0$ & $>4.0$ & \\
\hline Knee & 6.9 & 3.9 & 33.7 \\
\hline Ref. & & & 40 \\
\hline $\begin{array}{l}\text { Right } \\
\text { Peroneal } \\
\text { Tibialis } \\
\text { anterior } \\
\end{array}$ & & & \\
\hline Fibular head & 12.4 & 2.5 & \\
\hline Ref. & $<4.0$ & $>4.0$ & \\
\hline Knee & 14.4 & 2.2 & 48.3 \\
\hline Ref. & & & 40 \\
\hline
\end{tabular}


started on IVIg ( $2 \mathrm{~g} / \mathrm{kg}$ body weight over 5 days), resulting in improvement of strength with residual pinprick sensation deficit only in the toes and reduced vibration in his feet from his previous neuropathy two months after treatment.

\section{Discussion}

Guillain-Barre syndrome (GBS) is the most common acute inflammatory demyelinating polyneuropathy preceded by infection with bacteria or viruses. It is worth noting that over 50 cases of GBS were reported until today, secondary to only Herpes Zoster infection. ${ }^{3}$ In a study by Parra et al., the association of GBS with Zika Virus infection was established. The role of cross-reactive immunogenicity and molecular mimicry plays a vital role in the development of the disease. ${ }^{4}$

The temporal association of the development of autoimmune neuromuscular disorders and vaccine administration is well documented. Several vaccines, although beneficial, have proposed to be implicated in the development of autoimmune disorders, especially GBS. The precise mechanism is unknown, but one probable cause could be the vaccine components eliciting an exaggerated immune response. As stated earlier, the Shingrix vaccine consists of the glycoprotein E and adjuvant ASO1B. Adjuvants, by definition, are substances that augment antigen-specific immune response. ${ }^{5}$

However, studies reported the role of adjuvants in causing autoimmunity by molecular mimicry and simulating an immune reaction in animal models or humans similar to the bacterial or viral infections. ${ }^{5}$ Recently, Yadav et al. reported the first case of GBS presented ten days after the Shingrix vaccination in a 76-year-old female, as seen in our case. ${ }^{3}$

The flu vaccine, Tetanus toxoid, BCG, Rabies, Smallpox, Hepatitis B, MMR, Diphtheria, and Poliovirus vaccines are attributed to GBS's development. ${ }^{3,5}$ Boe et al. described the case of a 14-year-old who developed GBS within two weeks after the human diploid cell rabies vaccine. ${ }^{6}$ Khamaisi et al. reported a 52- year-old woman who developed GBS after her second injection of hepatitis B vaccine. ${ }^{7}$ However, there are controversies in terms of establishing the causality of GBS secondary to vaccine administration. Chen et al., in their study on the role of the vaccine in causing GBS, they reported that there is no increased risk of GBS development after vaccinations in both adult and pediatric population groups. Their results are contrary to three meta-analyses that established the association between GBS and influenza vaccination. ${ }^{8}$
Although hypothesized that the Shingrix vaccine may have led to GBS in our patient, the exact pathogenesis is still not clear. In addition to the adjuvants, immune responses directed against the Glycoprotein E can also result in autoantibodies or T-cell activation that cross-react with ganglioside GM1 in the myelin resulting in immunological damage to the peripheral nerve sheaths. Further in vitro studies will be required to assess this relationship.

\section{Corresponding author}

Raghav Govindarajan MD

One hospital drive

Department of Neurology

University of Missouri Health Care

Columbia. MO.USA. 65201

Email: govindarajanr@health.missouri.edu

\section{References}

${ }^{1}$ Yawn BP, Saddier P, Wollan PC, St Sauver JL, Kurland MJ, Sy LS. (2007) A population-based study of the incidence and complication rates of herpes zoster before zoster vaccine introduction, Mayo Clin Proc, vol. 82(pg. 1341-9) doi:10.4065/82.11.1341

${ }^{2}$ F. Maltz, B. Filder. Shingrix: A New HerpesZoster Vaccine. P.T. 2019; 44(7): 406-409,433.

${ }^{3}$ Yadav R, Hundley D, Cation L (2019) Severe Guillain-Barré Syndrome Following Shingrix ${ }^{\otimes}$ Vaccine Administration. J Neurol Neurosci Vol.10 No.4:301. DOI: 10.36648/2171-6625.10.4.301

${ }^{4}$ Parra B, Lizarazo J, Jiménez-Arango JA, Zea-Vera AF, González-Manrique G, Vargas J, Angarita JA, Zuñiga G, Lopez-Gonzalez R, Beltran CL, Rizcala KH. GuillainBarré syndrome associated with Zika virus infection in Colombia. New England Journal of Medicine. 2016 Oct 20;375(16):1513-23.

${ }_{5}^{5}$ Vered Molina, Yehuda Shoenfeld. (2005) Infections, Vaccines and Other Environmental triggers of Auto-immunity. Autoimmunity. 38(3):235-45. doi: 10.1080/08916930500050277.

${ }^{6}$ Boe E, Nyland H. (1980) Guillain-Barré syndrome after vaccination with human diploid cell rabies vaccine. Scand J Infect Dis. 12(3):231-2.doi: 10.3109/inf.1980.12.issue-3.12

${ }^{7}$ M. Khamaisi, Y. Shoenfeld, H. (2004) Orbach Guillain-Barré syndrome following hepatitis B vaccination. Clin Exp Rheumatol, 22 pp. 767-770.

${ }^{8}$ Chen Y, Zhang J, Chu X, Xu Y, Ma F. Vaccines and the risk of Guillain-Barré syndrome. European journal of epidemiology. 2020 Apr;35(4):363-70. 